\title{
Potencialidades do ensino de Biologia por Investigação
}

\author{
DANIELA LOPES SCARPA I \\ e NATÁLIA FERREIRA CAMPOS II
}

\section{O consenso construtivista e a Alfabetização Científica}

A S MUDANÇAS que ocorreram na educação ao longo do tempo são bem relatadas na literatura (por exemplo, em Krasilchik, 2000; Cachapuz et al., 2005 ) e revelam alterações nas concepções sobre os processos de ensino e de aprendizagem. Se pudéssemos resumir em um único aspecto as principais mudanças que ocorreram na educação, especialmente no século XX, o papel de professor e estudantes no processo de ensino e de aprendizagem seria o foco. De uma concepção na qual o professor era tido como detentor do conhecimento que poderia ser transmitido unidirecionalmente para um aluno que o recebia de maneira passiva e como uma tábula rasa, hoje acredita-se que os estudantes estão no centro do processo de ensino e de aprendizagem (ou, pelo menos, deveriam estar), agindo ativamente na construção do conhecimento, a partir de conhecimentos que já possuem sobre os fenômenos, por meio de oportunidades oferecidas pelos professores.

John Dewey (1959, p.104) afirmava, já em 1916, que "provavelmente, a causa mais frequente pela qual a escola não consegue garantir que os alunos pensem verdadeiramente é que não se provê uma situação experimentada, de tal natureza que obrigue a pensar, exatamente como o fazem as situações extraescolares", defendendo a importância da experiência vivida pelos estudantes na resolução de problemas que fazem sentido e permitem mobilizar os conceitos envolvidos nas mais diversas áreas de conhecimento.

As ideias construtivistas, que tomaram forma no campo da educação nos meados dos anos 1960-1970, permitiram essa mudança de foco no papel de professor e estudantes. Apesar de construtivismo ser um conceito amplo e que tem se esvaziado no nosso tempo, por conta de um uso generalizado que não necessariamente implica reflexos nas práticas educacionais, pode-se defender um consenso construtivista, que reúne três aspectos principais: a valorização das concepções prévias dos estudantes, a importância das interações entre indivíduo e objeto de conhecimento e a necessidade das interações sociais na construção do conhecimento (Novak, 1988; Gil-Pérez et al., 1999; Carvalho, 2013).

Dois desses aspectos são tributários da obra de Jean Piaget (biólogo e psicólogo suíço, 1896-1980). O primeiro deles diz respeito à valorização dos conhecimentos prévios dos estudantes ao se ensinar um tópico ou conteúdo. Contrário à 
noção de tábula rasa, em que o indivíduo não sabe nada sobre o assunto e todo o aprendizado provém da experiência externa, de fora para dentro, o consenso construtivista prevê que as concepções ou conhecimentos prévios dos estudantes sejam trazidos para a sala de aula como forma de embasar a construção de novos conhecimentos. O segundo ponto se refere à ideia de que o conhecimento não está fora do sujeito, se impondo a ele, nem está preformado no seu interior, sendo inato a ele, mas a sua construção é resultado da interação entre o externo e o interno, da interação entre o sujeito e os objetos e fenômenos. É nas ações de interação que as estruturas cognitivas e as representações sobre o mundo são construídas, e essas, por sua vez, permitem ao indivíduo se adaptar e responder ao meio, gerando mais e diferentes interações, e assim por diante (Piaget, 1973).

Além dessas interações, a dinâmica educativa deve considerar o caráter cultural, histórico e social do processo de construção de conhecimento, incorporando em sua dimensão as interações sociais como mediadoras desse processo e o significativo papel da linguagem na elaboração de raciocínios sobre o mundo. Com grande influência de Lev Vygotsky (psicólogo russo, 1986-1934), que afirmava que "todas as funções no desenvolvimento da criança aparecem duas vezes: primeiro, no nível social e, depois, no nível individual; primeiro entre pessoas (interpsicológico) e, depois, no interior da criança (intrapsicológico)" (Vygotsky, 1998, p.75), o papel das interações na sala de aula por meio da linguagem ganha importância para se propiciar o aprendizado.

As aulas expositivas, demasiadamente centradas no professor, não contribuem para que os estudantes sejam os atores do seu aprendizado, na medida em que não consideram as concepções prévias, não possibilitam as interações entre sujeito e objeto de conhecimento, nem a interação entre os pares. Para que a mudança de foco do papel de professor e alunos realmente aconteça em sala de aula, é necessário que o professor reflita sobre sua prática e desenvolva estratégias didáticas que permitam esse deslocamento, essa mudança de função.

Do ponto de vista da educação científica, mudanças significativas também ocorreram com relação ao papel e aos objetivos do ensino de Ciências ao longo do tempo. Se nas décadas de 1950-1960 o componente curricular de ciências estava comprometido a formar uma elite que se interessasse em seguir carreira científica para garantir a hegemonia norte-americana na conquista do espaço ou para impulsionar o processo de industrialização brasileiro (Krasilchik, 2000), hoje testemunhamos a contribuição do ensino de disciplinas científicas na formação integral do estudantes, ou seja, em uma formação que permita a construção de ferramentas cognitivas para que o indivíduo possa se posicionar e tomar decisões bem informadas em um mundo repleto de tecnologia e ciência (Scarpa; Sasseron; Silva, 2017).

Assim, de um ensino que privilegiava os conteúdos conceituais e teóricos da ciência (aprender ciências) e em que as atividades práticas ou experimentais serviam tão somente para motivar os estudantes ou comprovar aquilo que foi 
ensinado em uma aula expositiva, os objetivos do ensino de Ciências passaram a contemplar conhecimentos sobre como os conceitos e teorias são construídos, possibilitando o desenvolvimento de compreensões sobre as características da investigação científica, o papel e o status do conhecimento gerado nas investigações, as dificuldades enfrentadas pelos cientistas, a validade das conclusões científicas e as relações entre ciência, tecnologia, sociedade e ambiente (aprender sobre ciências), além de proporcionar aos estudantes oportunidades de se envolverem em práticas científicas e resoluções de problemas (aprender a fazer ciências) (Hodson, 2014).

Essas diferentes dimensões dos objetivos do ensino de Ciências foram sistematizadas nos três eixos estruturantes do que se convencionou chamar de Alfabetização Científica (Sasseron; Carvalho, 2011, p.75-76):

- Compreensão básica de termos, conbecimentos e conceitos científicos fundamentais: construção, pelos estudantes, de conhecimentos científicos necessários para que seja possível a eles aplicá-los em situações diversas e de modo apropriado em seu dia a dia.

- Compreensão da natureza das ciências e dos fatores éticos e políticos que circundam sua prática: ideia de ciência como um corpo de conhecimentos em constantes transformações por meio de processo de aquisição e análise de dados, síntese e decodificação de resultados que originam os saberes.

- Entendimento das relações existentes entre ciência, tecnologia, sociedade e meio ambiente: identificação do entrelaçamento entre essas esferas. Necessidade de se compreender as aplicações dos saberes construídos pelas ciências considerando as ações que podem ser desencadeadas pela utilização dos mesmos.

Um indivíduo alfabetizado cientificamente deve, portanto, compreender o que a ciência é, o que ela não é, como as investigações científicas são realizadas para produzir conhecimento, como o raciocínio e as explicações científicas são construídos e como a ciência contribui com a cultura e é influenciada por ela. Esses aprendizados seriam potencializados por meio de oportunidades de os estudantes vivenciarem investigações científicas (NRC, 1996).

O importante é que, ao longo da escolarização, esses três eixos sejam tratados de maneira equilibrada (como representado na Figura 1), de forma que os estudantes tenham oportunidades diferenciadas de aprenderem não somente conceitos, princípios, leis e teorias científicas, mas possam vivenciar, refletir sobre e compreender os procedimentos e raciocínios pelos quais eles foram elaborados, que isso pode ter se modificado ao longo do tempo e que pode ter limitações e influências na sociedade, além de sofrer influências dela.

Ao terem a oportunidade de desenvolver aprendizados sobre os três eixos da Alfabetização Científica, os estudantes podem encontrar mais motivações para os temas relacionados à ciência e elaborar raciocínios baseados em evidências para sustentar suas tomadas de decisões nos assuntos em que estão imersos no seu cotidiano. 


\section{Alfabetização}

\section{Científica}

Aprender Ciências

\section{Aprender}

a fazer

Ciências
Aprender sobre Ciências

Fonte: Elaborada pelas autoras.

Figura 1 - Representação das relações entre os três eixos da Alfabetização Científica na Educação Básica.

Ao terem a oportunidade de desenvolver aprendizados sobre os três eixos da Alfabetização Científica, os estudantes podem encontrar mais motivações para os temas relacionados à ciência e elaborar raciocínios baseados em evidências para sustentar suas tomadas de decisões nos assuntos em que estão imersos no seu cotidiano.

O que acontece, no entanto, majoritariamente, tanto nos materiais didáticos disponíveis aos professores como nas salas de aulas de Ciências da Educação básica, é uma ênfase na descrição e definição de conceitos e teorias presentes na ciência, ou seja, os cursos de ciências apresentam seu enfoque no primeiro eixo da Alfabetização Científica de maneira desarticulada dos outros eixos que, quando presentes, muitas vezes têm a função de ilustrar e/ou corroborar aquilo que foi exposto pelo professor. Essa relação desigual está representada na Figura 2.

Como mudar esse cenário? Como criar oportunidades para que os estudantes desenvolvam aprendizados sobre os três eixos da Alfabetização Científica e possam compreender o papel da ciência na sociedade e construir conhecimentos e posicionamentos articulados que possam servir para outras esferas de suas vidas?

Os aspectos relacionados ao consenso construtivista ajudam a pensar em formas pedagógicas de se atingir a Alfabetização Científica em sala de aula, uma vez que a atividade científica também está pautada pelos conhecimentos produzidos historicamente. Assim como os conhecimentos prévios são importantes para que os estudantes transformem as suas estruturas cognitivas e construam novos conhecimentos, os novos conhecimentos na ciência são produzidos com 


\section{Tradicionalmente...}

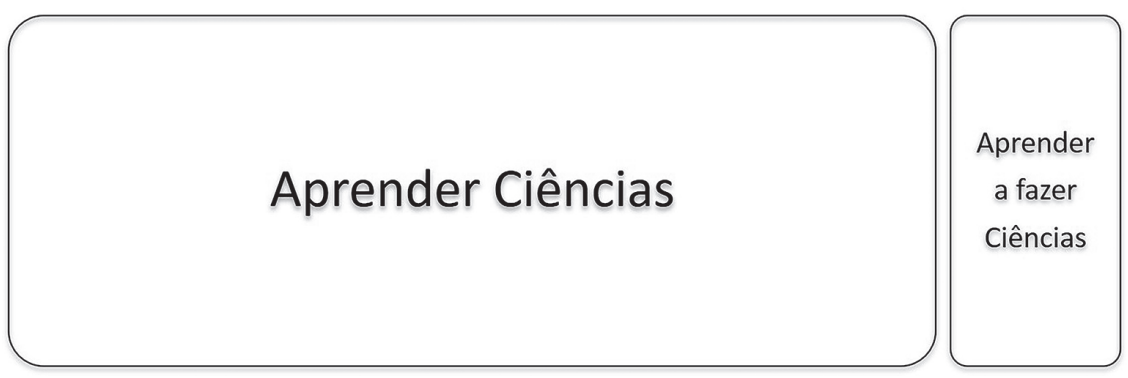

Fonte: Elaborada pelas autoras.

Figura 2 - Tradicionalmente, o aprendizado de conteúdos conceituais é favorecido nas salas de aulas de Ciências da Educação Básica e, quando atividades práticas e experimentais estão presentes, servem para ilustrar ou corroborar os conteúdos vistos nas aulas teóricas.

base na articulação, avaliação, reformulação e até abandono dos conhecimentos disponíveis em um determinado momento histórico. Além disso, as práticas científicas envolvem a interação do pesquisador com os objetos de conhecimento, visto que os cientistas agem sobre os fenômenos que estão investigando, isolando algumas de suas partes, provocando reações, comparando situações etc.; ao realizar essas interações, é possível tirar conclusões sobre o todo, articular variáveis, compreender o fenômeno ou parte dele diante das ferramentas (instrumentais e/ou teóricas) disponíveis, assim como ocorre no processo de aprendizagem. Por outro lado, a atividade científica é social por natureza, já que são as interações entre pares que permitem que os enunciados sejam avaliados, legitimados, refutados ou transformados em um processo complexo de argumentação e persuasão, no qual evidências, explicações e formas de representações dos fenômenos investigados são utilizadas para convencimento de uma comunidade, o que pode levar ao estabelecimento de consensos ou dissensos.

Como forma de aproximar os princípios construtivistas com os da Alfabetização Científica na prática da sala de aula, são necessárias estratégias didáticas que promovam o engajamento dos estudantes em práticas e processos investigativos de maneira que haja a compreensão de como o trabalho científico é desenvolvido. Nessa perspectiva, o ensino por investigação tem sido a abordagem didática mais conhecida e estudada (Kang; Keinonem, 2018) e que tem o potencial de articular os três eixos da Alfabetização Científica de forma construtivista. 


\section{O Ensino de Ciências por Investigação}

O Ensino de Ciências por Investigação (EnCI) está pautado pela ideia do uso de estratégias didáticas que buscam envolver ativamente os alunos em sua aprendizagem, por meio da geração de questões e problemas nos quais a investigação é condição para resolvê-los, com coleta, análise e interpretação de dados que levem a formulação e comunicação de conclusões baseadas em evidências e reflexão sobre o processo (Melville et al., 2008). Nesse sentido, o ensino por investigação é mais do que uma estratégia didática ou uma metodologia de ensino, é uma perspectiva de ensino ou uma abordagem didática (Sasseron, 2015) em que as estratégias utilizadas servem ao propósito de possibilitar a realização de uma investigação pelos estudantes por meio da mediação do professor.

Uma forma de operacionalizar o EnCI em sala de aula é por meio do ciclo investigativo, em que fases de uma investigação são identificadas e conectadas com o propósito de auxiliar o professor no planejamento e aplicação de atividades ou sequências didáticas investigativas. A partir de uma revisão sistemática de literatura com o objetivo de sumarizar os aspectos centrais do EnCI, Pedaste et al. (2015) propuseram uma síntese do ciclo investigativo, representado na Figura 3.

A fase de orientação envolve o processo de estimular a curiosidade dos estudantes sobre um assunto, levantando e/ou elaborando problemas que possam ser investigados em sala de aula. Esses problemas podem ser atacados por meio de questões de investigação, orientadas em conceitos, teorias ou hipóteses (fase de conceitualização). Por exemplo, o problema da crise hídrica da cidade de São Paulo de 2014 pode ser investigado por meio de questões relacionadas ao papel das mudanças climáticas na diminuição da quantidade de chuva na cidade no período ou por meio de questões relacionadas a urbanização e gestão pública. É a questão que vai dar sentido a toda a investigação dos estudantes. Por um lado, engajar os estudantes na resolução de problemas contribui para que os estudantes compreendam que a ciência funciona criando e resolvendo problemas. Por outro, essas fases podem contribuir para a valorização dos conhecimentos prévios dos estudantes e para o desenvolvimento de uma postura investigativa perante o mundo, em que eles podem articular a sua capacidade de observação e descrição da realidade com marcos teóricos disponíveis e com a sua curiosidade para problematizar o mundo.

Para responder à questão de investigação, a fase de investigação propõe que dados e informações sejam coletados por meio das mais diversas estratégias. A experimentação é uma metodologia específica, mais relacionada com o teste de hipóteses, enquanto a exploração permite o uso de diversas estratégias para coleta, organização e sistematização dos dados e informações relevantes que poderão se constituir como evidências para a construção de explicações que respondam à questão. A utilização de diversas estratégias didáticas na perspectiva do EnCI pode contribuir para o desenvolvimento de visões mais adequadas sobre as diversas formas de produção de conhecimento científico, além de contemplar diversos perfis de alunos e estilos de ensinar (Scarpa; Silva, 2013). 


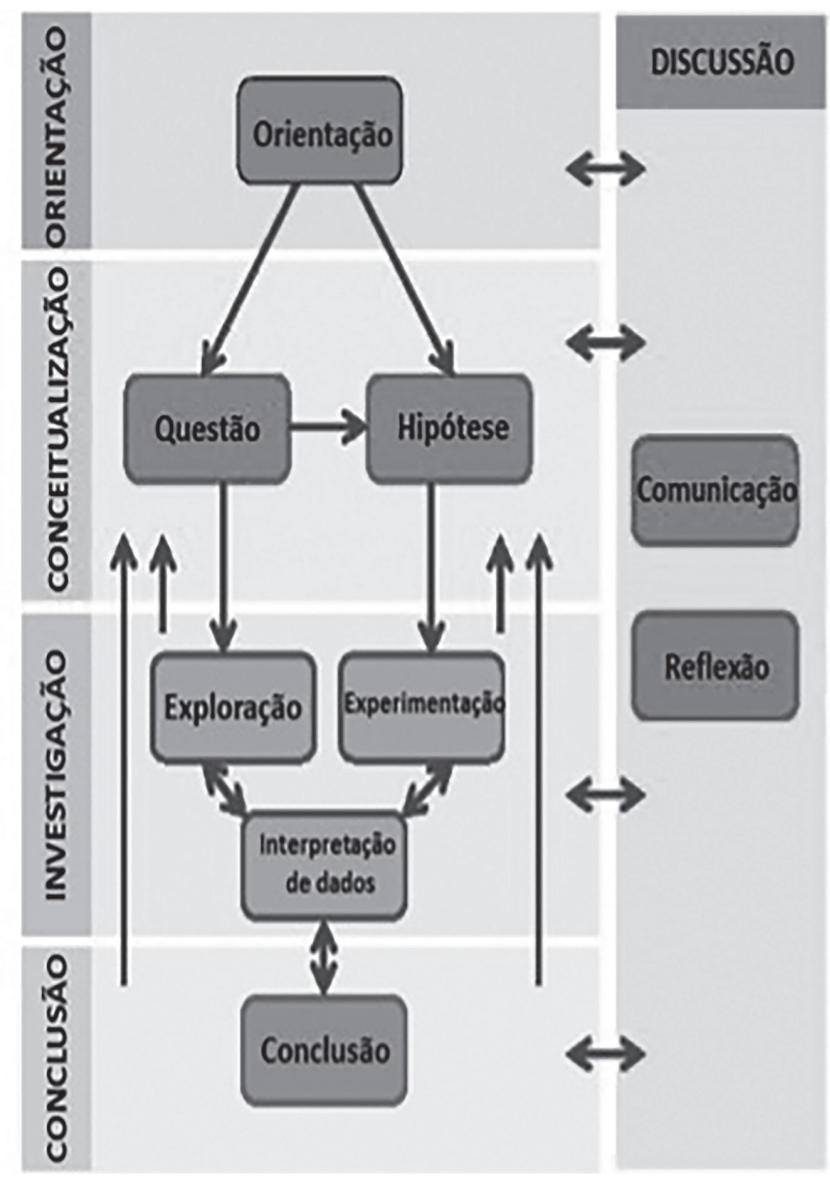

Fonte: Traduzido de Pedaste et al. (2015, p.56).

Figura 3 - Representação do ciclo investigativo proposto por Pedaste et al. (2015).

$\mathrm{Na}$ interpretação dos dados, os conceitos são mobilizados para explicar os dados e novos conhecimentos são construídos. Para isso, aspectos da linguagem matemática e da linguagem científica são demandados, como na organização de tabelas, elaboração de gráficos, identificação de padrões. Todo esse processo pode oferecer para os estudantes a dimensão do trabalho criativo e rigoroso envolvido nas ciências, como também possibilitar a busca ativa por procedimentos de coleta, análise e sistematização de dados na tentativa de construírem compreensões sobre os fenômenos estudados.

Na fase de conclusão é esperado que os estudantes construam explicações, afirmações ou posicionamentos que respondam à questão de investigação. Nela também pode ocorrer a comparação com as hipóteses formuladas na fase de conceitualização. Apesar de a argumentação estar presente em todo o ciclo investigativo, é na fase de conclusão que os argumentos finais, que articulam as evidências, os conhecimentos prévios e científicos e a explicação, são construídos ou sistematizados (Figura 4). 


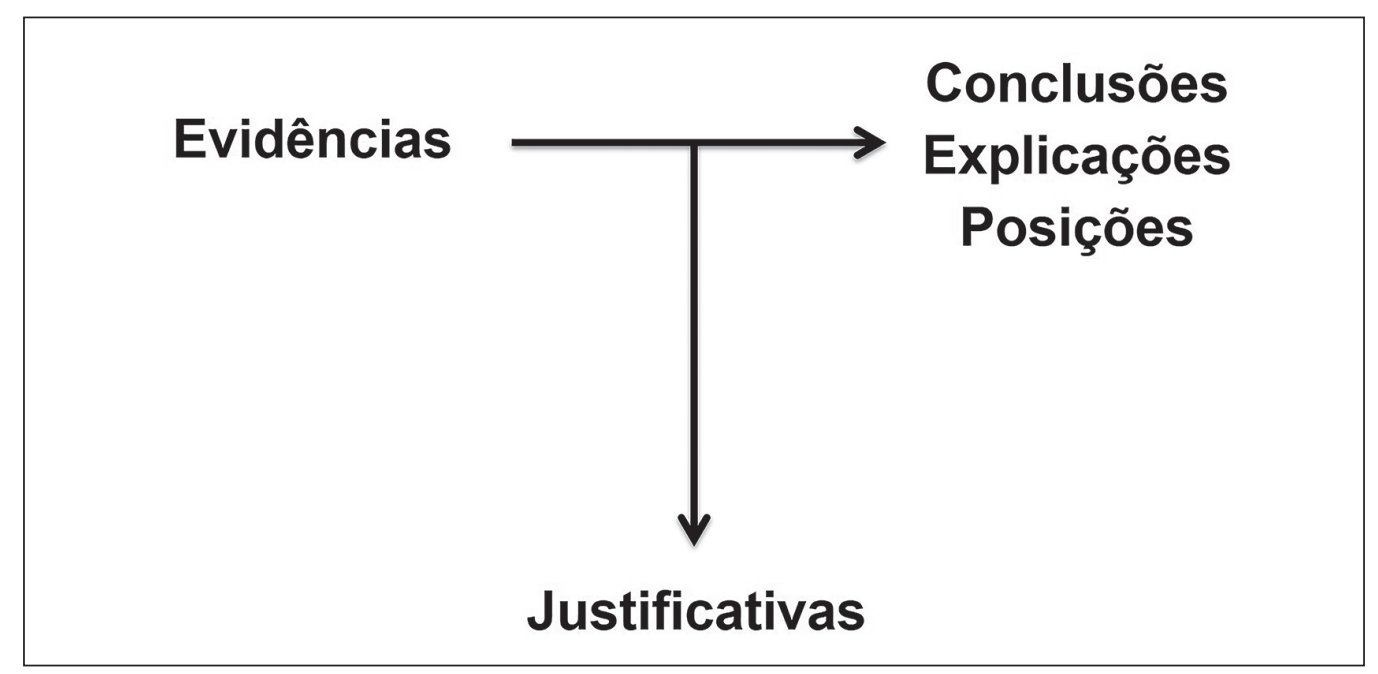

Fonte: Elaborada pelas autoras.

Figura 4 - Representação de um argumento na perspectiva da justificação de afirmativas de conhecimento (Jiménez-Aleixandre; Erduran, 2008). As conclusões/explicações/posicionamentos são construídas com base em evidências, que advêm da seleção de dados relevantes para a sua construção. Essa relação é embasada em conhecimentos que justificam o porquê dessas evidências sustentarem as conclusões.

Se, por um lado, a construção e avaliação de explicações com base em evidências é uma atividade central dos cientistas na produção de conhecimento; por outro, o raciocínio argumentativo está presente em todas as esferas da sociedade, já que permite “a formulação de boas razões para as afirmações proferidas, assim como a avaliação das razões fornecidas por outros sobre suas ideias e ações" (Scarpa, 2015, p.18). Portanto, a vivência pelos estudantes em situações em que tenham a oportunidade de desenvolver esse tipo de raciocínio é fundamental na educação científica de forma a possibilitar a compreensão das formas como a ciência funciona (contemplando especialmente o segundo eixo da Alfabetização Científica), ao mesmo tempo que contribui com a formação crítica dos estudantes, empoderando-os com ferramentas cognitivas para tomar decisões embasadas ou avaliar afirmações no seu cotidiano.

Finalmente, a fase de discussão contempla a apresentação e comunicação dos resultados obtidos em uma das fases ou em todo o processo investigativo. O trabalho em pequenos grupos e a sistematização com a turma toda permitem que as interações entre pares e entre professores e estudantes aconteçam, favorecendo a organização, a discussão e a avaliação das ideias que marcam o processo de aprendizagem.

Ressalta-se que engajar os estudantes em práticas científicas, como proposto no EnCI, não é suficiente para que eles desenvolvam conhecimentos sobre as ciências (segundo e terceiro eixos da Alfabetização Científica), ou seja, fazer não é suficiente para aprender sobre (Osborne, 2016). É necessário também 
refletir sobre essas práticas, ter oportunidades para compreender o que conta como evidência, o papel dessas evidências na construção de explicações, como definir os critérios para considerar certas explicações melhores do que outras, quais as limitações das explicações, enfim, para compreender como os cientistas agem para conferir confiabilidade e credibilidade aos conhecimentos produzidos (Osborne, 2016). A fase de reflexão do ciclo investigativo prevê justamente esse aspecto do empreendimento científico, ao recomendar que haja oportunidades para a avaliação, crítica e legitimação dos procedimentos, ações e conhecimentos construídos pelos estudantes ao longo de toda a investigação, constituindo um momento essencial de regulação da aprendizagem, além de prever também que os estudantes possam imaginar novas questões e novas situações em que aquele conhecimento poderia ser aplicado, originando novos ciclos de investigação.

\section{Um exemplo no ensino de Biologia}

A Biologia pode ser uma das disciplinas escolares mais interessantes ou mais enfadonhas para os estudantes, dependendo do modo como ela for abordada. A motivação dos estudantes com os temas de ensino é um aspecto fundamental para a promoção da aprendizagem. Explorar os temas fazendo conexões com o cotidiano dos estudantes ou com os debates presentes na mídia é uma forma de gerar interesse levando ao envolvimento afetivo necessário ao engajamento nas atividades. Nesse sentido, a vida cotidiana oferece uma gama de oportunidades que podem ser exploradas do ponto de vista dos conceitos biológicos.

O comportamento e o desenvolvimento humano, os processos de saúde e doença, assim como a relação das pessoas com o ambiente despertam interesse na compreensão sobre os organismos vivos e suas inter-relações. Vacinar ou não os filhos? Reduzir ou não o controle do uso de agrotóxicos? Consumir ou não alimentos transgênicos? Desastres ambientais, terapias gênicas, exames laboratoriais, teste de paternidade e toda a gama de novas tecnologias associadas ao DNA, combate a epidemias, questões de gênero e sexualidade e vegetarianismo são temas de interesse da população e que demandam algum conhecimento no âmbito das ciências biológicas para a sua compreensão e o seu julgamento de maneira informada.

Questões como essas trazidas para a escola são particularmente interessantes para o desenvolvimento do terceiro eixo estruturante da Alfabetização Científica, em que são estabelecidas relações entre conceitos, modelos e ideias científicas relevantes às tomadas de decisões necessárias na vida em sociedade. Para que essas decisões aconteçam com algum embasamento ou mesmo para avaliar afirmações que circulam publicamente, é fundamental compreender como se constroem evidências ou se produzem generalizações confiáveis na ciência, ou seja, como os conhecimentos científicos são produzidos, avaliados e legitimados (Gott; Duggan, 2007).

Levar o ensino de Ciências por investigação para a sala de aula não é tarefa simples. O professor precisa articular os conhecimentos pedagógicos e biológicos 
em situações de aprendizagem que sejam adequadas e relevantes para um determinado grupo de estudantes inserido em um contexto específico, o que pode ser desafiador mesmo para professores experientes (Crawford; Capps, 2018). Portanto, para superar a visão comum de um ensino de Biologia memorístico e sobrecarregado de conceitos descontextualizados (Munford; Lima, 2007) é necessário que os processos de formação propiciem aos (futuros) professores compreender e se apropriar das formas de fazer ciência, assim como de abordagens pedagógicas diferentes da tradicional aula expositiva e que incluam possibilidades de interações dos estudantes com os objetos de conhecimento e entre os pares.

Nesse sentido, na disciplina de Estágio Supervisionado em Ensino de Biologia, da Licenciatura em Ciências Biológicas do Instituto de Biociências da USP, os licenciandos têm a oportunidade de entrar em contato com os aspectos teóricos sobre o ensino de Ciências por Investigação e, na prática de estágio, vivenciar o exercício da profissão, planejando e executando, com o apoio da equipe docente, uma Sequência Didática Investigativa (SDI). A SDI produzida pelos licenciandos deve estar fundamentada nos princípios do consenso construtivista e nos eixos da Alfabetização Científica, por meio da organização das atividades em um ciclo investigativo. Além disso, a SDI deve estar direcionada para uma turma de estudantes conhecida a partir da fase de observação da escola-campo de estágio e das conversas com os professores responsáveis.

Nesse contexto, os licenciandos podem refletir sobre e lidar com os desafios e as possibilidades do uso da abordagem do ensino de Ciências por Investigação. Descrevemos a seguir, de forma simplificada, uma das SDI produzidas no âmbito da disciplina. ${ }^{1}$

Tema: transgênicos.

Série: $2^{\circ}$ ano do Ensino Médio.

Número de aulas previsto: 5 aulas.

Objetivos: construir o conceito de organismo transgênico a partir da interpretação de textos e imagens.

Pergunta da SDI: O que são transgênicos?

Fase de orientação: Para engajar os estudantes no tema e, ao mesmo tempo, explorar os conhecimentos prévios que possuíam, foram disponibilizados alguns produtos de supermercado para que os estudantes, em pequenos grupos, classificassem os produtos em transgênicos e não transgênicos, explicitando os critérios utilizados para a classificação. Os produtos foram: pepinos; pacote de arroz; óleo de soja; amido de milho; biscoito; pó de café; salgadinho; ração de gato e mistura pronta para bolo.

Fase de conceitualização: Nessa discussão inicial em pequenos grupos, e depois com toda a turma e professores, os estudantes puderam expor suas ideias e ouvir os colegas sobre o que seria um alimento transgênico. Essas ideias iniciais serviriam de subsídio para a interpretação dos textos e imagens que seriam disponibilizados a seguir para os estudantes responderem o que são transgênicos. 
Fase de investigação: Os estudantes, em grupos, receberam um conjunto de fichas com textos e imagens. Todos os grupos receberam um conjunto de fichas com informações sobre Biologia molecular, que continham representações da fita de DNA e dos genes, do processo de transcrição e tradução do DNA na produção de proteínas. Cada grupo recebeu um segundo conjunto de fichas com informações sobre um organismo transgênico específico: algodão Bt mais resistente ao ataque de alguns insetos; arroz dourado produtor de betacaroteno; milho com o gene da produção de hormônio de crescimento humano hGH; soja modificada para maior resistência a estresse hídrico e tomate roxo por produção de antocianina (Figura 5).

A partir da leitura e análise das fichas, e dos livros didáticos disponíveis para consulta, era esperado que os estudantes respondessem a dois blocos de perguntas, entregues a eles em momentos subsequentes:

1.a. Onde o DNA está localizado na célula?

1.b. O que é um gene?

l.c. Como é possível combinar o DNA de dois organismos diferentes?

2.a. Com qual finalidade foi feito o seu transgênico?

2.b. De qual organismo foi retirado o gene? Em qual organismo ele foi inserido?

2.c. Como foi feito o seu transgênico? Para responder, relacione o maior número de informações que puder (textos, imagens, gráficos e tabelas).

As respostas foram entregues, lidas e devolvidas com comentários, algumas vezes questionamentos, que ajudassem os alunos a reelaborarem as respostas incompletas ou incorretas.

Fase de comunicação e conclusão: Com a turma de estudantes em roda, cada grupo apresentou as informações sobre seu transgênico e foi registrada uma síntese com a sistematização das informações: organismo que doou o gene, organismo que recebeu o gene, como o transgênico foi produzido e com qual finalidade foi produzido. A partir dessa sistematização, questionou-se o que era comum entre os transgênicos. Esperava-se que os estudantes notassem que o processo de produção era o mesmo em todos os casos, ou seja, havia a transferência de um gene de um organismo para outro, por meio da Agrobacterium tumefaciens.

Fase de conclusão e reflexão: Retomou-se as concepções iniciais que os estudantes apresentaram sobre transgênico na primeira atividade solicitando que eles as reavaliassem. Era esperado que, nesse momento, os estudantes pudessem responder à pergunta inicial "o que são transgênicos". Solicitou-se que retomassem a classificação dos produtos realizadas na primeira aula para repensarem a classificação e observarem as embalagens, buscando responder como poderíamos identificar os transgênicos. Os estudantes puderam concluir que não é possível saber se um produto é transgênico apenas pela sua aparência, além 


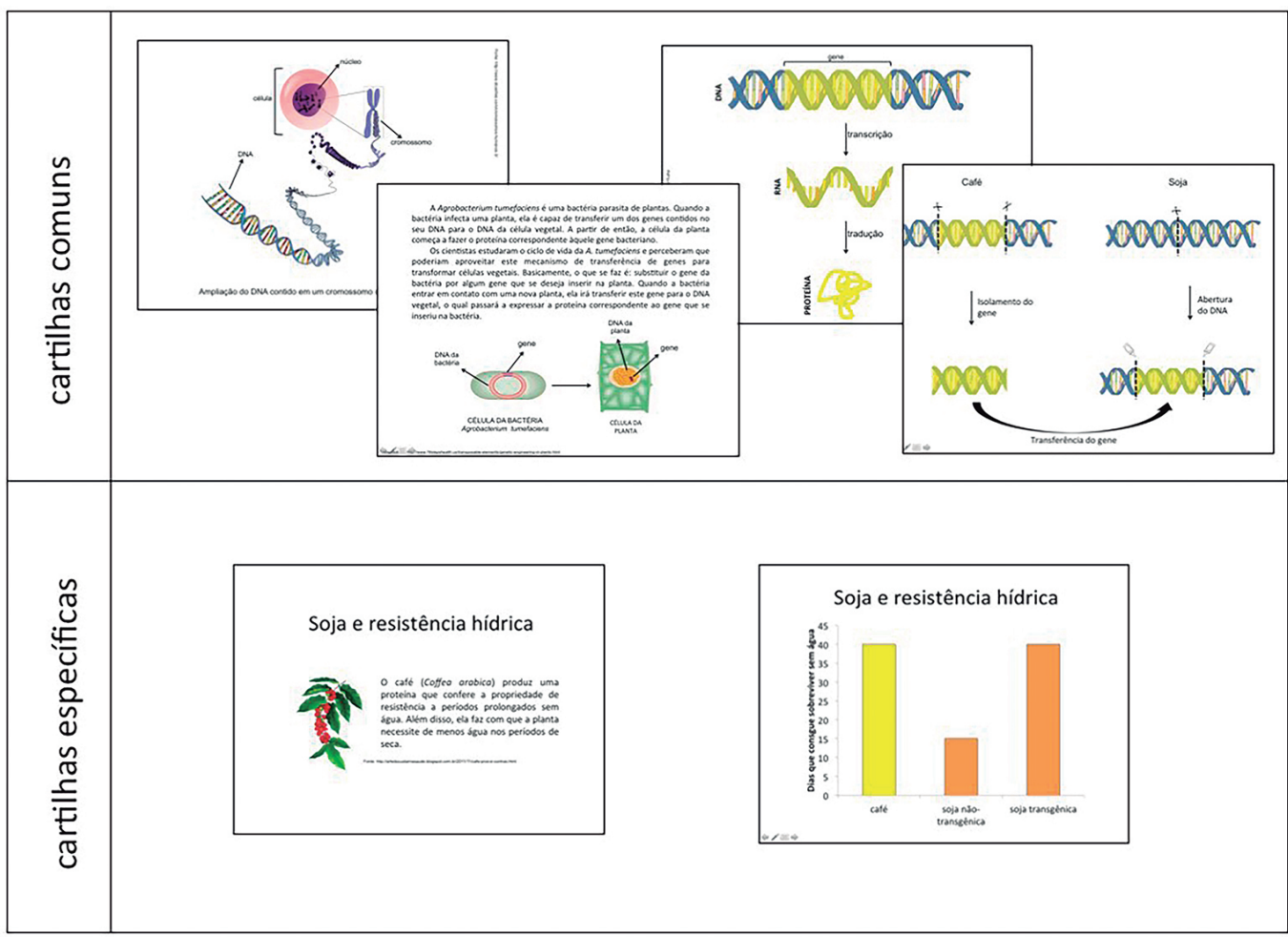

Fonte: Elaborada pelos licenciandos Bunni Costa, Carolina Mendonça e Isabela Castro em 2016.

Figura 5 - Exemplo de fichas distribuídas aos grupos de estudantes. As fichas comuns eram semelhantes entre todos. As fichas específicas variavam entre os grupos.

de observarem no rótulo do amido de milho que contém $A$. tumefaciens. Na discussão final com a turma toda apareceram novos questionamentos dos estudantes sobre questões éticas e de transgenia em animais, que foram respondidos brevemente. Os estudantes deveriam registrar a resposta final à questão principal e avaliar seu percurso de aprendizagem ao longo da sequência didática.

Para analisar essa sequência, é necessário considerar o contexto de sua produção. Essa é a primeira experiência de regência dos licenciandos, em que têm a oportunidade de planejar e executar um conjunto de aulas sobre determinado tema. A partir das primeiras observações do estágio e das conversas com os professores, os licenciandos precisariam planejar atividades que articulassem objetivos e estratégias de aprendizagem sobre um tema acordado com o professor da turma, de acordo com o ensino de ciências por investigação. As atividades deveriam ser adequadas aos conhecimentos e habilidades dos aprendizes e deveriam considerar as limitações do tempo disponibilizado pela escola para a regência e dos recursos materiais. Assim, as sequências produzidas são resultantes da superação desses desafios característicos dessa fase inicial do exercício da profissão e do contexto de estágio. 
A sequência didática apresentada pode ser caracterizada como uma investigação estruturada (Banchi; Bell, 2008), na qual a pergunta e os dados necessário para respondê-la foram fornecidos aos estudantes, que por sua vez foram responsáveis por realizar a análise e interpretação dos dados para tecer uma conclusão. A questão de investigação proposta é uma questão conceitual, que poderia ser respondida de forma direta a partir de uma definição existente; no entanto, as atividades foram organizadas de modo a conduzir o raciocínio dos estudantes, possibilitando que eles construíssem o conceito de transgênico com base em seus conhecimentos prévios, nas informações disponibilizadas nas fichas, textos e mercadorias, assim como a partir das interações discursivas que ocorreram em sala de aula, respeitando, portanto, os princípios do consenso construtivista.

Nota-se, na primeira atividade, uma preocupação em conectar o tema com aspectos do cotidiano dos estudantes como estratégia para engajá-los na SDI, visto que os produtos transgênicos têm sido comercializados em torno de um constante debate sobre sua segurança alimentar e, mais recentemente, sobre a questão ética de transparência, com a tramitação do PLC 34/2015 (BRASIL, 2015) que propõe eliminar a indicação da presença de componentes transgênicos quando esses estiverem presentes em porcentagem inferior a $1 \%$ da composição total do produto alimentício.

$\mathrm{Na}$ análise das informações das fichas, os estudantes puderam ter contato com formas de representação típicas da ciência, como imagens de microscopia eletrônica, gráficos de barras, tabelas e esquemas. Eles procederam à interpretação e seleção de informações que conduzissem às explicações solicitadas na atividade. No caso dessa SDI, percebe-se que não há um paralelo explícito entre a análise dos dados em relação ao que acontece na ciência, mesmo assim, os estudantes organizam e classificam informações, desenvolvendo habilidades de análise da linguagem científica, o que os aproxima do segundo eixo da Alfabetização Científica, referente às práticas das ciências.

Ao final da atividade, os estudantes são levados a comunicar os resultados de seu trabalho de análise das fichas para a turma, em um processo de reflexão coletiva que atua como regulador da aprendizagem pelos próprios estudantes, assim como pelo professor que tem a oportunidade de avaliar, trazer novas informações e reflexões, contextualizando as práticas realizadas em relação à área de conhecimento. É nesse momento também que, ao comparar os resultados de cada grupo, os estudantes podem enxergar padrões nos diferentes tipos de transgênicos para construir uma generalização que responde à questão de investigação. Assim, o próprio cenário de comunicação entre os grupos faz parte do processo investigativo.

Por fim, a atividade desperta nos estudantes novos questionamentos sobre as questões éticas e a clonagem de animais, que poderiam gerar novos ciclos investigativos que contemplassem outros aspectos da Alfabetização Científica, como aqueles mais ligados às relações entre ciência, sociedade, tecnologia e ambiente. 
A sequência apresentada, como uma primeira experiência dos licenciandos, traz subsídios interessantes sobre as possibilidades de se trabalhar temas de Biologia por meio do ensino por investigação. A partir da atividade de planejamento, replanejamento e aplicação, os licenciandos puderam refletir e reformular, não só a sequência, incorporando novos elementos, mas repensar a sua prática docente de maneira mais ampla, incorporando novas formas de ensinar. As fases do ciclo investigativo orientaram a produção da SDI, ressaltando momentos importantes para a aprendizagem como o engajamento inicial, a análise de dados e a reflexão sobre o processo, auxiliando os professores a pensarem em formas de situarem os estudantes como parte ativa e central no processo de aprendizagem.

\section{Comentários finais}

Apesar de toda a potencialidade que o ensino por investigação apresenta para que o professor organize suas aulas de Biologia na perspectiva da Alfabetização Científica, Hodson (2014) nos alerta que o ensino por investigação em geral é mal concebido. Há um mito recorrente de que o ensino por investigação na escola é o mesmo do que realizar investigações científicas na ciência, mimetizando a atividade dos cientistas. O ensino por investigação é mais amplo do que o fazer ciência, envolvendo o uso de diversas estratégias didáticas para coletar dados e informações que permitam alguma analogia ou construção de conceitos científicos. Além disso, os tempos, os espaços, as motivações para a realização da investigação e seus objetivos são muito diferentes: enquanto na ciência pretende-se construir conhecimentos novos sobre o mundo, na escola, espera-se que os estudantes construam conhecimentos e habilidades novos para si mesmos. Algumas características das práticas científicas são inspiradoras para a elaboração de perspectivas pedagógicas que possibilitem o desenvolvimento do raciocínio argumentativo, do pensamento crítico e de uma postura investigativa sobre o mundo.

Assim, o objetivo do ensino por investigação na educação científica não é formar cientistas ou reproduzir a ciência na escola, mas propiciar aos estudantes um ambiente de aprendizagem em que possam questionar, agir e refletir sobre os fenômenos, construindo conhecimentos e habilidades e desenvolvendo autonomia de pensamento. Tudo isso de forma ativa, interativa e colaborativa.

Nota

1 Essa sequência didática foi produzida no primeiro semestre de 2016 pelos licenciandos Bunni Costa, Carolina Mendonça e Isabela Castro.

\section{Referências}

BANCHI, H.; BELL, R. The many levels of inquiry. Science and Children, v.46, n.2, p.26-9, 2008. 
BRASIL. Projeto de Lei da Câmara n.34, de 2015. Câmara dos Deputados. Altera a lei de Biossegurança. Diário do Senado Federal, Brasília, DF, 5 mai. 2015 Disponível em: <https://www25.senado.leg.br/web/atividade/materias/-/materia/120996> Acesso em: 7 ago. 2018

CACHAPUZ, A. et al. (Org.) A necessária renovação do ensino de ciências. São Paulo: Cortez, 2005.

CARVALHO, A. M. P. de. O ensino de Ciências e a proposição de sequências didáticas investigativas. In: . (Org.) Ensino de Ciências por investigação: condições para implementação em sala de aula. São Paulo: Cengage Learning, 2013. cap.1, p.1-20.

CRAWFORD, B. A.; CAPPS, D. K. Teacher cognition of engaging children in scientific practices. In: DORI, J.; MEVARECH, Z.; BAKER, D. (Ed.) Cognition, metacognition, and culture in STEM Education. New York: Springer, 2018. cap.2, p.9-32.

DEWEY, J. Democracia e educação: introdução à filosofia da educação. 3.ed. São Paulo: Nacional, 1959.

GIL-PÉREZ, D. et al. ¿Puede hablarse de consenso Constructivista en la educación Científica? Enseñanza de las Ciencias, v.17, n.3, p.503-12, 1999.

GOTT, R.; DUGGAN, S. A framework for practical work in science and scientific literacy through argumentation. Research in Science \& Technological Education, v.25, n.3, p.271-291, 2007.

HODSON, D. Learning science, learning about science, doing science: different goals demand different learning methods. International Journal of Science Education, v.36, n.15, p.2534-53, 2014.

JIMÉNEZ-ALEIXANDRE, M. P.; ERDURAN, S. Argumentation in Science Education: an overview. In: ERDURAN, S.; JIMÉNEZ-ALEIXANDRE, M. P. (Ed.) Argumentation in Science Education: Perspectives from Classroom-Based Research. Dordrecht: Springer, 2008. p.3-27.

KANG, J.; KEINONEN, T. The Effect of Student-Centered Approaches on Students' Interest and Achievement in Science: Relevant Topic-Based, Open and Guided Inquiry-Based, and Discussion-Based Approaches. Research in Science Education, v.48, n.4, 2018.

KRASILCHIK, M. Reformas e realidade: o caso do ensino de ciências. São Paulo em Perspectiva, v.14, n.1, 2000.

MELVILLE, W.; FAZIO, X.; BARTLEY, A.; JONES, D. Experience and reflection: preservice science teachers' capacity for teaching inquiry. Journal of Science Teacher Education, v.19, n.5, p.477-94, 2008.

MUNFORD, D.; LIMA, M. E. C. de C. E. Ensinar ciências por investigação: em quê estamos de acordo? Ensaio Pesquisa em Educação em Ciências, v.9, n.1, p.89-111, 2007.

NATIONAL RESEARCH COUNCIL [NCR]. National Science Education Standards. Washington: National Academy Press, 1996.

NOVAK, J. D. Constructivismo humano: un consenso emergente. Enseñanza de las ciencias, v.6, n.3, p.213-23, 1988.

OSBORNE, J. Defining a knowledge base for reasoning in science: the role of procedural and epistemic knowledge. In: DUSCHL, R. A.; BISMARCK, A. S. (Ed.) Recon- 
ceptualizing STEM Education: the central role of practice. New York: Routledge, 2016. p.215-31.

PEDASTE, M. et al. Phases of inquiry-based learning: Definitions and the inquiry cycle. Educational Research Review, v.14, p.47-61, 2015.

PIAGET, J. Psicologia e epistemologia: por uma teoria do conhecimento. Rio de Janeiro: Forense, 1973.

SASSERON, L. H. Alfabetização científica, ensino por Investigação e Argumentação: relações entre Ciências da Natureza e Escola. Ensaio Pesquisa em Educação em Ciências, v.17, n.espec, 2015.

SASSERON, L. H.; CARVALHO, A. M. P de. Alfabetização científica: uma revisão bibliográfica. Investigações em Ensino de Ciências, v.16, n.1, p.59-77, 2011.

SCARPA, D. L. O papel da argumentação no ensino de ciências: lições de um workshop. Ensaio Pesquisa em Educação em Ciências, v.17, n.espec, 2015.

SCARPA, D. L.; SASSERON, L. H.; SILVA, M. B. e. O Ensino por Investigação e a Argumentação em Aulas de Ciências Naturais. Tópicos Educacionais, v.3, n.1, p.7-27, 2017.

SCARPA, D. L.; SILVA, M. B. A Biologia e o ensino de Ciências por investigação: dificuldades e possibilidades. In: CARVALHO, A. M. P. de. (Org.) Ensino de Ciências por Investigação: condições para implementação em sala de aula. São Paulo: Cengage Learning, 2013. cap.8, p.129-52.

VYGOTSKY, L. S. Pensamento e linguagem. São Paulo: Martins Fontes, 1998.

RESUMO - A Biologia pode ser uma das disciplinas escolares mais interessantes ou mais enfadonhas para os estudantes, dependendo do modo como ela for abordada. Articulando aspectos do consenso construtivista com os eixos da Alfabetização Científica, este artigo pretende mostrar as potencialidades do ensino por investigação para o ensino de Biologia, de forma a torná-lo mais significativo aos estudantes. Sequências didáticas baseadas no ensino por investigação podem ampliar os objetivos do ensino de Biologia na perspectiva da Alfabetização Científica, permitindo situar os estudantes no centro do processo de ensino e aprendizagem de modo que desenvolvam compreensões sobre conceitos e teorias, sobre o processo de produção de conhecimento e sobre as relações entre ciência, tecnologia, sociedade e ambiente.

PALAVRAS-CHAVE: Ensino de Ciências por investigação, Alfabetização científica, Consenso construtivista, Ensino de Biologia.

ABSTRACT - Biology may be one of the most interesting or boring school subjects for students depending on how it is approached. Articulating aspects of the constructivist consensus with the dimensions of Scientific Literacy, this article intends to show the potential of inquiry-based science learning in Biology teaching to make it more meaningful to students. The didactic sequences of inquiry-based learning can broaden the goals of Biology teaching from the perspective of Scientific Literacy, allowing students to be placed at the center of the teaching and learning process to develop their understanding of concepts and theories, of the process of knowledge production and of the relationship between science, technology, society and the environment. 
KEYWORDS: Inquiry-based science teaching, Scientific literacy, Constructivist consensus, Biology teaching.

Daniela Lopes Scarpa é professora do Departamento de Ecologia do Instituto de Bio-ciências da USP. Possui licenciatura e bacharelado em Ciências Biológicas pelo Instituto de Biociências da USP, mestrado e doutorado em Educação/Ensino de Ciências pela Faculdade de Educação da USP. @ - dlscarpa@usp.br

Natália Ferreira Campos é doutoranda em Ensino de Biologia pelo Programa de Pós-graduação Interunidades em Ensino de Ciências-USP. Mestre em Ensino de Ciências na modalidade Biologia pela Universidade de São Paulo, bacharel e licenciada em Ciên cias Biológicas pelo Instituto de Biociências da USP.

@ - natafcampos@gmail.com

Recebido em 13.8.2018 e aceito em 2.9.2018.

${ }^{\text {I }}$ Departamento de Ecologia, Instituto de Biociências, Universidade de São Paulo, São Paulo, São Paulo, Brasil.

II Programa de Pós-Graduação Interunidades em Ensino de Ciências, Universidade de São Paulo. São Paulo, São Paulo, Brasil. 
